\title{
THE EAR OXIMETER : \\ ITS USE CLINICALLY AND IN THE DETERMINATION OF CARDIAC OUTPUT
}

\author{
BY \\ H. R. GILMORE, M. HAMILTON, H. KOPELMAN, AND L. S. SOMMER * \\ From the Department of Medicine, Postgraduate Medical School of London \\ Received November 10, 1953
}

Following the basic research into the photometric characters of oxyhæmoglobin and reduced hæmoglobin by Nicolai (1932) and Kramer (1934), Matthes described the first oximeter in 1935. The early oximeters used only visible red light for the recording of oxygen saturation and so were not compensated for variations in hæmoglobin concentration unless indirectly, through plethysmography. Matthes, later, was the first to use light absorption in two spectral regions differently absorbed by oxygenated and reduced hæmoglobin and so was able to compensate for variations in hæmoglobin concentration.

The demands of physiological research in aviation medicine during the 1939-45 war hastened the development of an ear oximeter suitable for clinical use. Many workers in the United States, among whom Millikan (1942) is outstanding, explored the technical problems presented by the construction of a satisfactory ear piece and recording circuit. The Millikan oximeter, however, needed to be calibrated for full saturation in each patient, and was therefore of little use in assessing absolute values needed in cyanotic states.

Wood and Geraci (1949) by the use of suitable circuit re-arrangements and a pressure capsule built in the oximeter head, have modified the Millikan oximeter to give absolute arterial oxygen saturation readings. An instrument of this type, a commercial model, $\uparrow$ has been used by the present workers. By attaching a Cambridge dropping plate camera and a time-marker, recording one second intervals, a permanent photographic record of the galvanometer beam deflection can be obtained. This instrument has now been in use in this department for some two years. In the following paper we record our experiences with it used as a clinical adjunct in the determination of arterial oxygen saturation and an extension of its use with Evans Blue dye (T.1824) in the determination of mean circulation time and cardiac output.

\section{Methods OF Using THE OXIMETER}

Determination of Arterial Saturation and Calibration. In order to achieve maximum vasodilatation in the ear, so that skin blood became arterialized, the oximeter was placed on the pinna some 15 minutes before setting the instrument and starting readings. In most subjects, the warmth from the light contained in the oximeter head was sufficient to produce such dilatation. In the minority, however, it was found necessary to apply a cream with a vasodilator action (due to nicotinamide as its main constituent) to the pinna before adjusting the oximeter. Since the application of this cream, in some instances, resulted in local odema, causing fluctuation in the oximeter readings, we have used the cream very sparingly.

As a preliminary to its use in clinical medicine, it was necessary to assess the accuracy of the

* Public Health Service Research Fellow of the National Heart Institute, U.S.A.

$\dagger$ Walters-Conley Company, Rochester, Minn., U.S.A. 
oximeter as a means of determining arterial oxygen saturation. This was done by simultaneous arterial sampling and oximetric readings in patients with anoxæmia, or in normal volunteers with induced anoxæmia. All blood gas analysis was done by one trained person using the method of Van Slyke and Neill (1924).

Because of the difficulty of maintaining a steady oxygen saturation in cases of induced anoxæmia, the calibration was made primarily on patients with anoxæmia. There were 28 observations in this group and they are marked by an open circle on the chart (Fig. 1). In 15 volunteers, 73 additional simultaneous observations were obtained and these are represented by a dot.

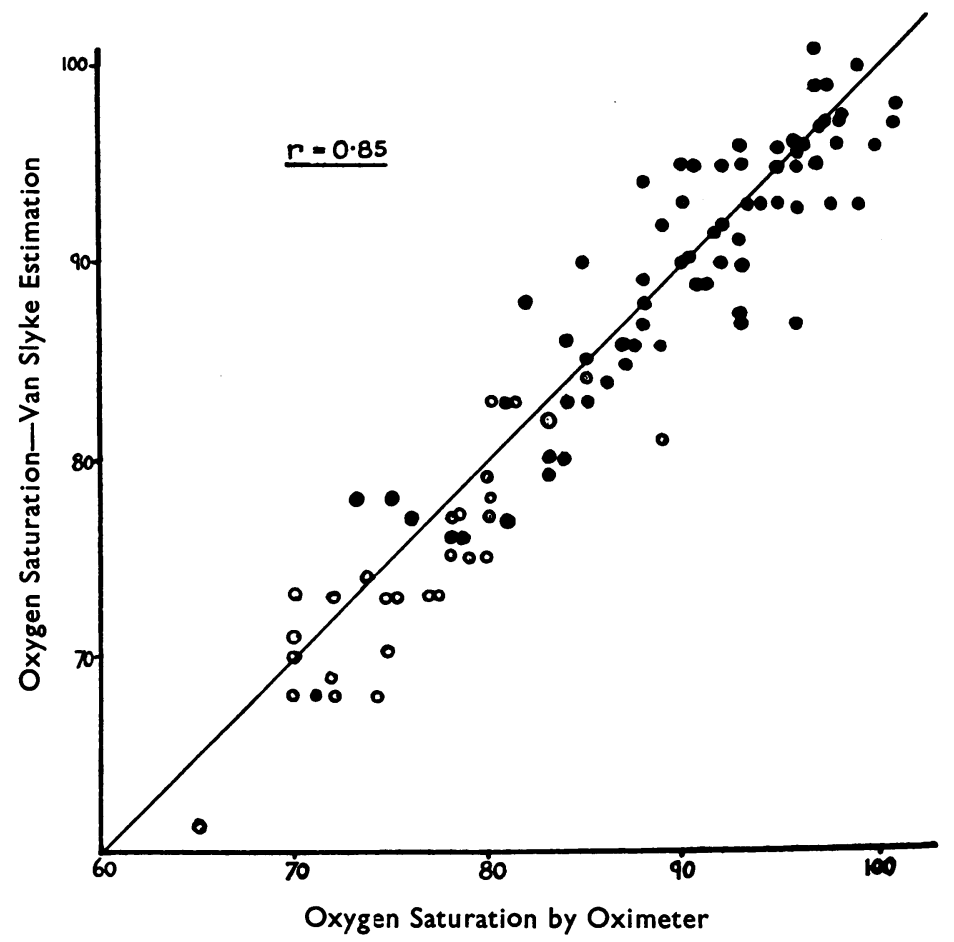

FIG. 1.-Comparison of arterial oxygen saturation determined by the oximeter and by simultaneous arterial blood sampling and estimation by the method of Van Slyke (see text).

The greatest number of observations fell in the range 70-95 per cent. Only four were made in patients where the saturation was less than 60 per cent, all of whom had polycythæmia, two of gross degree. As it had been decided to include observations only from subjects with a hæmoglobin range $12-15 \mathrm{~g}$. per $100 \mathrm{ml}$, these were excluded from the calibration. It can be seen from the results obtained (Fig. 1) that within the range of arterial oxygen saturation in which the instrument was tested, the mean difference between the oximeter reading and Van Slyke estimation was 3 per cent, varying between +10 and $-6 \cdot 7$ per cent. This is as accurate as the results to be expected from the occasional use of the Van Slyke apparatus. The merit of the instrument is probably not so much for recording absolute values of arterial oxygen saturation, as for measuring changes in arterial saturation that may occur under varying conditions.

Examples of its use in Measuring Arterial Oxygen Saturation. Used for determination of arterial oxygen saturation, the oximeter possesses immense possibilities in the investigation and management of patients suffering from cardiac and pulmonary disease. Many instances arise in management of such cases, in which knowledge of arterial oxygen saturation would be helpful. Gross cyanosis is easy to detect. However, it is common to hear experienced clinical opinion pondering this point where the anoxæmia is less definite. Furthermore, controlled experiment has shown 
that experienced observers (Comroe and Botellis, 1947) are unable to predict the degree of arterial unsaturation accurately from colour change. The problem is seldom resolved, as few instances justify arterial sampling and the subsequent time-consuming blood gas analysis. The use of the oximeter in children, where screaming and breath-holding during arterial sampling cause wide swings in saturation, is an obvious advantage.

Some of the effects on arterial oxygen saturation of oxygen administration and of exercise in various conditions are illustrated in Figs. 2 and 3. An excellent illustration of its use as an easy means of continuously recording arterial saturation has been in the study of patients suffering from Cheyne-Stokes respiration (Gilmore and Kopelman).

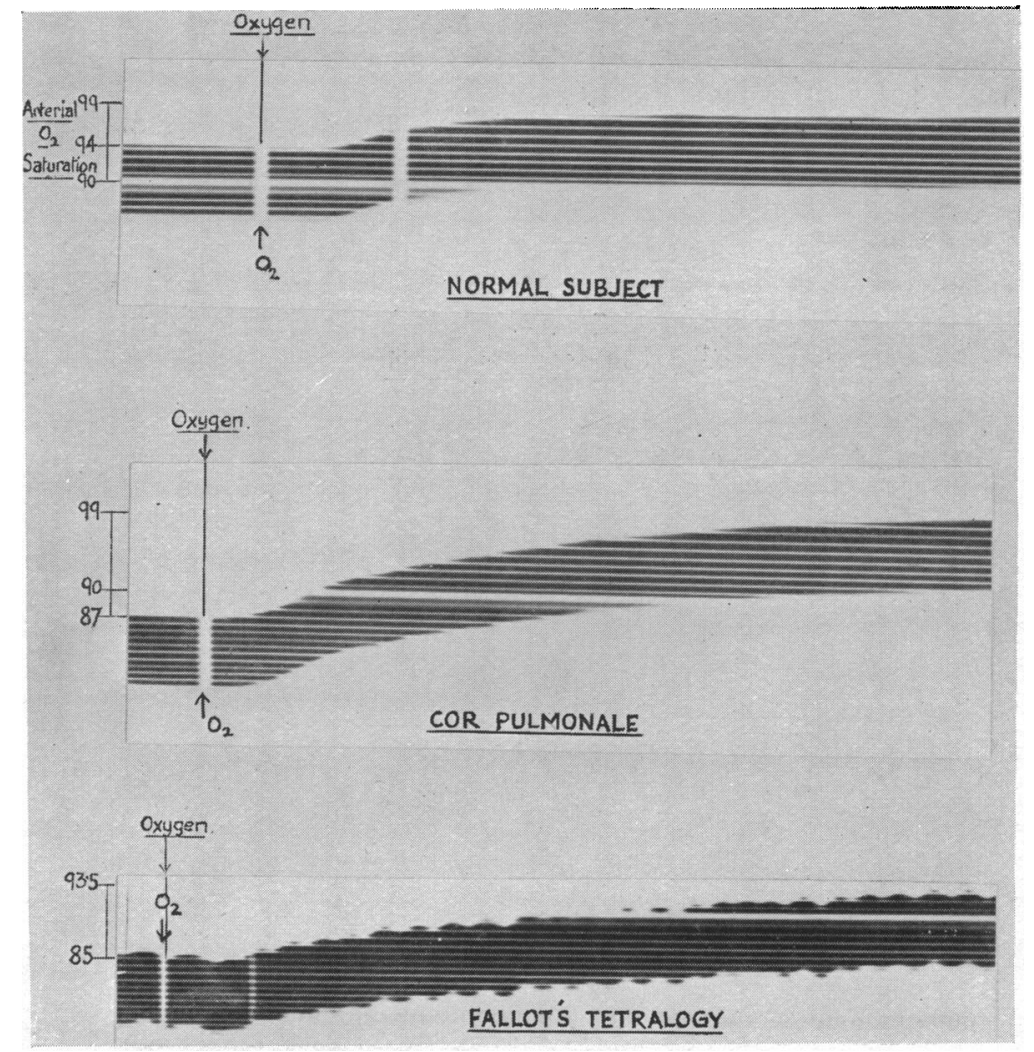

FIG. 2.-Use of the ear oximeter to demonstrate the rise in arterial oxygen saturation following the administration of oxygen by B.L.B. mask at 8 litres/min. The oxygen saturation is read from the top of the curve, each line representing 1 per cent change in saturation. All patients with Fallot's tetralogy showed a surprisingly high rise in saturation and a "scalloped" effect synchronous with respiration.

The Oximeter used in conjunction with Evans Blue Dye. Beard and Wood (1951) noted that the absorption characteristics of Evans Blue dye are such that a quantity of the dye passing in the blood stream will cause a deflection of the galvanometer beam. Using this dye injected intravenously, it is possible with this device to obtain photographic records of the time concentration curves. These compare closely in contour and time relationships with the curves constructed from serial arterial samples analysed for dye by the method described by Hamilton et al. (1932) (Fig. 4) and by Kopelman and Lee (1951).

From these curves the mean circulation time is calculated and, used in conjunction with the 


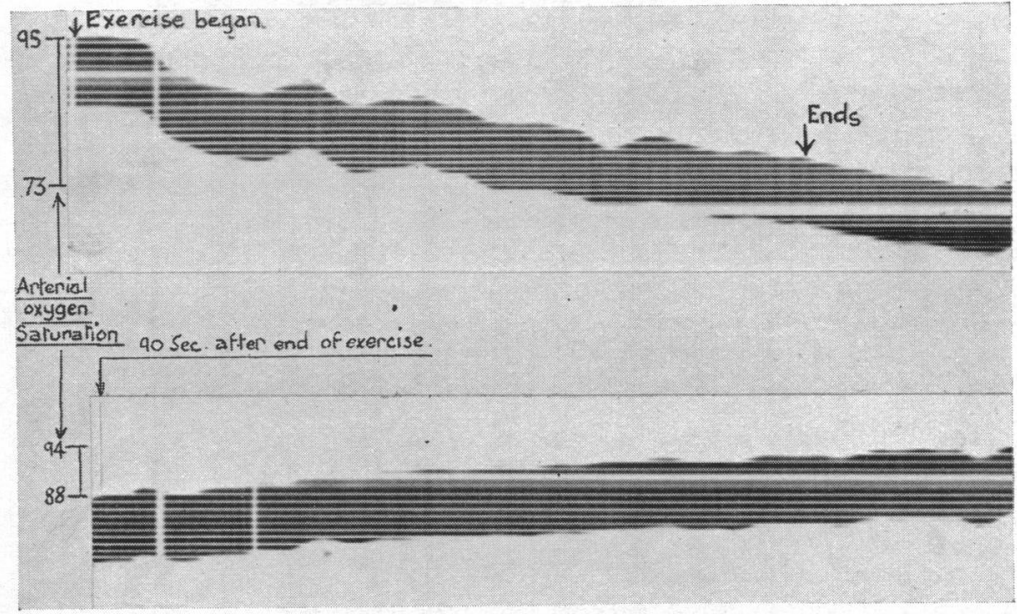

FIG. 3.-Use of the ear oximeter to demonstrate the effect of exercise upon the arterial oxygen saturation of a patient with pulmonary stenosis and auricular septal defect. During exercise the saturation fell from 95 to 73 per cent and $1 \frac{1}{2}$ minutes after the end of exercise was 88 per cent rising to 93 per cent.

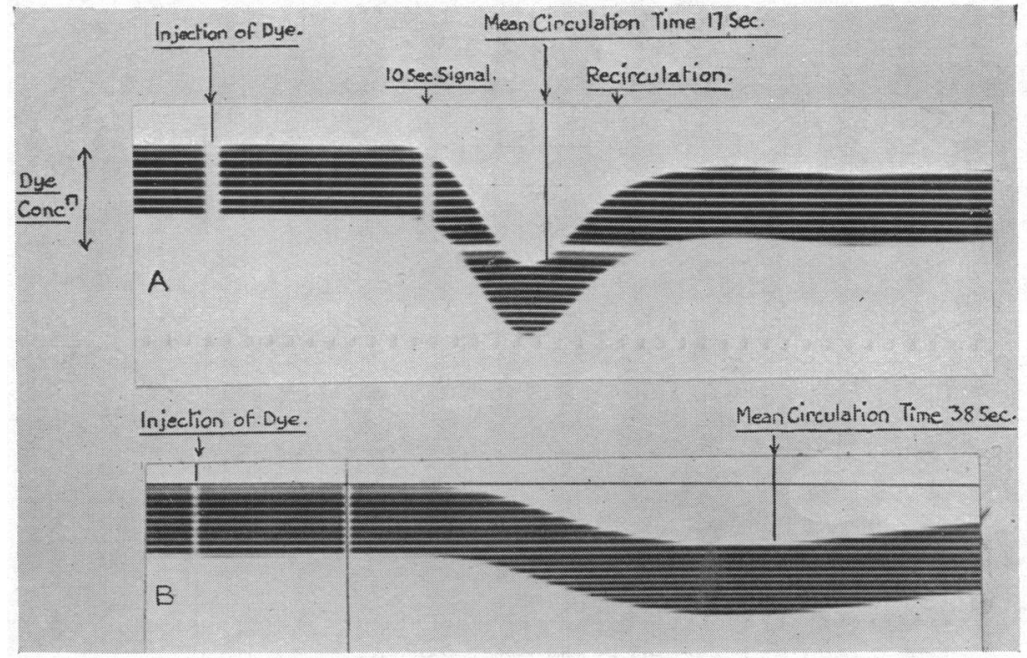

FIG. 4.-Time concentration curves obtained from recordings from the ear oximeter following the injection of $15-25 \mathrm{mg}$. of Evans Blue dye. (A) From normal subject. (B) Prolonged curve seen in patients with cardiac failure.

cardiac output obtained by the direct Fick method at cardiac catheterization or by oximetry (see below), may be used in the study of the intrathoracic blood volume (Gilmore et al., 1952).

The curve itself is of interest and worthy of study and the normal curve is depicted in Fig. 4. It shows an early deflection of the galvanometer with a short uniform curve and a return to a steady state within some 25 seconds, and the point of recirculation is seen clearly. In patients with cardiac failure or with very large hearts, the initial deflection is delayed, the curve itself protracted and flat, and the return to the steady state delayed for a considerable time. Characteristic abnormalities in the shape of the curve are seen in subjects with congenital heart disease with a shunt. It is usual, with a right-to-left shunt, to see an early rise in dye concentration followed by a second peak 
representing the true fastest circulation time, giving a double hump appearance to the curve. With a left-to-right shunt, the rise in dye concentration occurs at the normal time, but there is a prolonged and irregular fall off (Fig. 5).

It has been shown (Kopelman and Lee, 1951) that the ratio of the time taken for the first appearance of the dye to the mean circulation time was approximately one to two. This was fairly constant, not only in normal and large hearts but also in the presence of congestive failure.

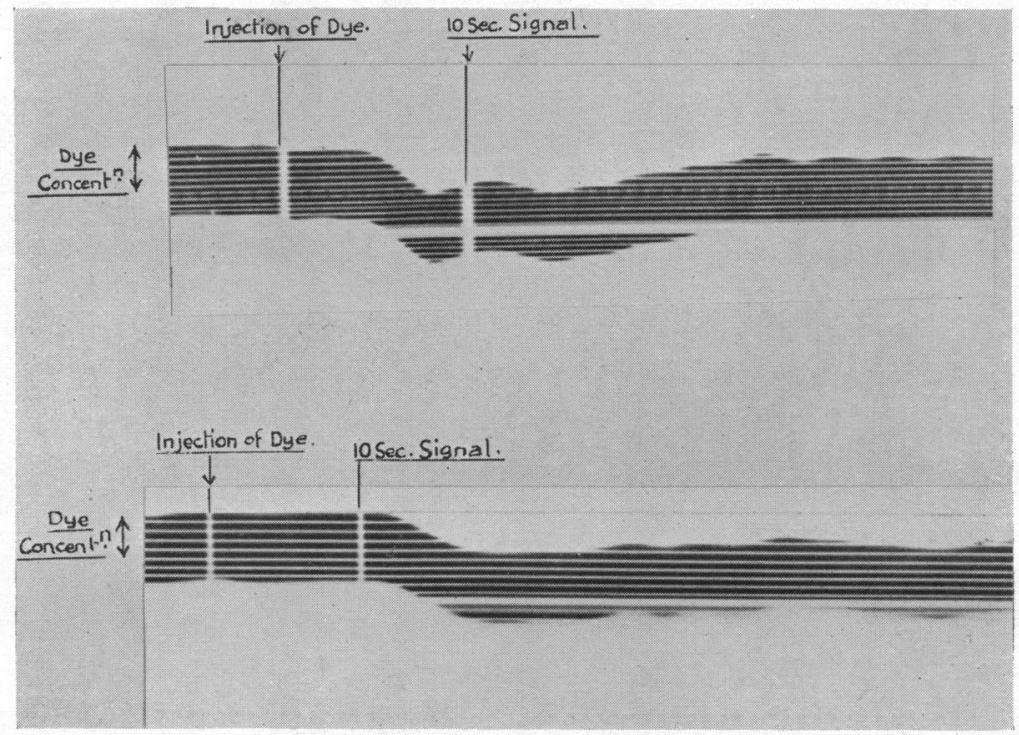

FIG. 5.-Time concentration curves obtained from patients with congenital heart disease. Note the early rise in concentration of dye followed by a second peak in (A), the right to left shunt. In (B) there is a normal rising concentration but a prolonged and irregular fall off.

The presence of a shunt alters this relationship and in cases of left-to-right shunt the ratio may be greatly increased. This is of value in differentiating curves that may be obtained in some patients with shunts and superficially resemble those seen in congestive failure.

In a large number of cases of congenital heart disease with both types of shunt, as proved by other special investigations, the dye curve never failed to demonstrate an abnormal pattern which was, however, difficult to interpret in some cases.

It was hoped that further analysis of the curves might give additional diagnostic information, but nothing conclusive has been found. Recently (1953) Swan et al., who first described the abnormal curves in congenital heart disease, have been able to calculate the actual flow that occurs in some cases of right-to-left shunt.

\section{Determinations of Cardiac OUTPUT}

The determination of cardiac output by the Hamilton dye technique (Hamilton, 1932) is already well established (Hamilton et al., 1948; Kopelman and Lee, 1951). Modifying this method to use the oximeter affords a technique free from danger and discomfort, save that of venepuncture. Before this technique can be claimed as one valid for the determination of cardiac output, we felt that it must fulfil the following criteria: (a) that outputs so obtained must not differ significantly from those obtained under the same conditions by other methods, namely, by the direct Fick principle, using cardiac catheterization, and by the Hamilton technique with intra-arterial sampling; and $(b)$ that duplicate output estimations must show no undue difference. 
Methods. The patient, in a fasting state, was rested in bed with the oximeter comfortably placed on the ear until a constant reading for oxygen saturation was obtained. Because of the sensitivity of the instrument to involuntary variations in respiration and consequent fluctuations in the baseline readings, the latter half of the subjects were given oxygen at 8 litres a minute by a B.L.B. mask throughout the procedure.

At a given signal, a quantity of Evans Blue dye, estimated at $15-20 \mathrm{mg}$., was injected rapidly into an antecubital vein, the exact dose of dye being obtained by weighing the syringe and needle before and after injection. Immediately after injection and removal of the needle from the vein, the arm was elevated and massaged briskly from the site of the injection to the axilla. The camera plate was released 10-15 seconds before the moment of injection and marks made at the time of injection and 10 seconds later, lest the timemarker should fail. A blood sample, required for calibration, was withdrawn 5-10 minutes after injection, when steady oximeter readings indicated that mixing was complete. It was shown by experiment that the response of the instrument to varying plasma concentrations of the dye was linear. The circulation curve of the dye was then calibrated by relating the plasma dye concentrations of the above sample to the amount of steady deflection of the galvanometer beam, noted after complete mixing. The curve thus calibrated was analysed by semi-logarithmic replotting (Hamilton et al., 1932), and the mean circulation time and cardiac output calculated by the usual method, involving the use of the hæmatocrit reading (Hamilton et al., 1948). The intrathoracic blood volume can be obtained using the mean circulation time and the cardiac output.

For the comparison with the outputs obtained by the Fick principle, known amounts of dye were injected through the cardiac catheter into the main pulmonary artery or right atrium, and samples taken for calibration when mixing was complete. Simultaneously, mixed venous samples and oxygen consumption were estimated for the Fick calculation in the usual way (McMichael and Sharpey-Schafer.1944).

\section{RESULTS}

Comparison with Cardiac Output obtained by Fick Principle. Twenty-five such comparisons were made upon patients who were subjected to cardiac catheterization for diagnosis and investigation of a variety of cardiac disorders other than congenital heart disease. The mean cardiac output of the Fick group was 5.1; that of the oximeter group was 5.5. In five of the twenty-five cases there was a difference of more than one litre between the methods; in two of these five the differences were considerable. However, in sixteen out of twenty-five, the differences were under one litre, and in some cases showed very close agreement. A statistical analysis, taking into account the error of both methods, showed no significant difference between the two, an analysis of variance giving a standard deviation of a single reading of $0 \cdot 7$. The results are illustrated in Fig. 6.

Comparison with Cardiac Output obtained by Hamilton Dye Method. Five such comparisons were made upon patients recovering from pulmonary infections. In view of the small numbers concerned, the results, shown in Table I, have not been subjected to statistical analysis.

Duplicate Estimations of Cardiac Output. These were made on 23 subjects, convalescent from a variety of conditions. The first estimation of cardiac output was done in the manner described, the second injection of dye being given immediately after the calibration sample was taken. The

TABLE I

Comparison of Cardiac Output determined by Hamilton Dye and Oximetry

\begin{tabular}{|c|c|c|c|c|c|}
\hline \multicolumn{3}{|c|}{ By Oximeter } & \multicolumn{3}{|c|}{ By Hamilton dye } \\
\hline $\begin{array}{l}\text { Cardiac output } \\
\text { (litres/minute) }\end{array}$ & $\begin{array}{l}\text { Mean circulation } \\
\text { time (sec.) }\end{array}$ & $\begin{array}{l}\text { Intrathoracic } \\
\text { blood volume } \\
\text { (litres) }\end{array}$ & $\begin{array}{l}\text { Cardiac output } \\
\text { (litres/minute) }\end{array}$ & $\begin{array}{c}\text { Mean circulation } \\
\text { time (sec.) }\end{array}$ & $\begin{array}{l}\text { Intrathoracic } \\
\text { blood volume } \\
\text { (litres) }\end{array}$ \\
\hline $\begin{array}{r}10.6 \\
7.4 \\
9 \cdot 1 \\
8.6 \\
7.0\end{array}$ & $\begin{array}{l}13 \\
20 \\
19 \\
28 \\
15\end{array}$ & $\begin{array}{l}2 \cdot 4 \\
2.5 \\
2.9 \\
3 \cdot 9 \\
1.6\end{array}$ & $\begin{array}{l}9 \cdot 0 \\
8 \cdot 1 \\
8 \cdot 8 \\
7 \cdot 0 \\
7 \cdot 9\end{array}$ & $\begin{array}{l}15.5 \\
22.0 \\
21.0 \\
25.0 \\
17.0\end{array}$ & $\begin{array}{l}2 \cdot 3 \\
2 \cdot 9 \\
3 \cdot 1 \\
3 \cdot 0 \\
2 \cdot 2\end{array}$ \\
\hline
\end{tabular}


results are shown in Table II; the means for the two series being 7.6 and 7.7 and the standard deviation of a single observation being 0.99. From these data we have calculated mean circulation times and intrathoracic blood volumes for each individual in both series, with equally good agreement in the results (Table II and Fig. 7).

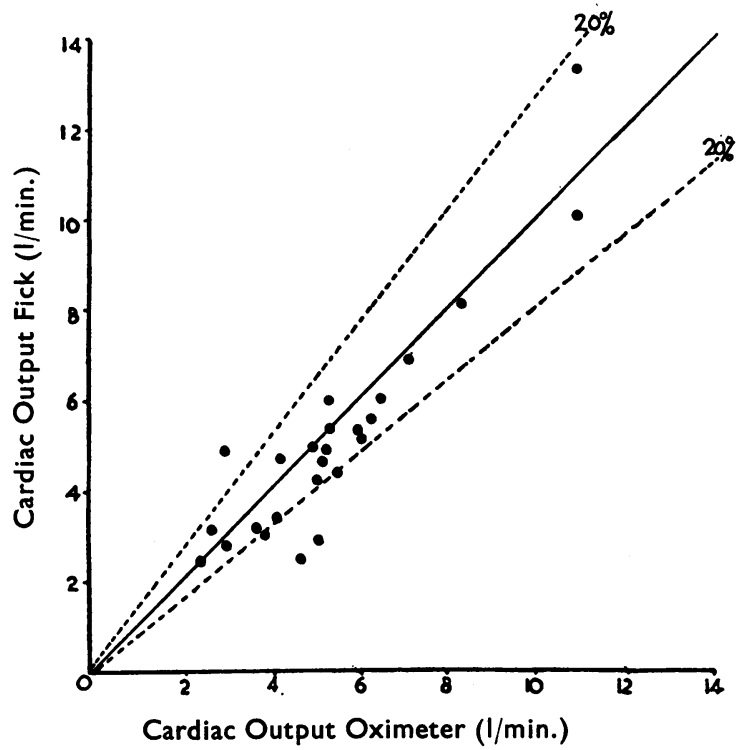

FIG. 6.-Comparison of cardiac outputs obtained by simultaneous oximeter and Fick methods.

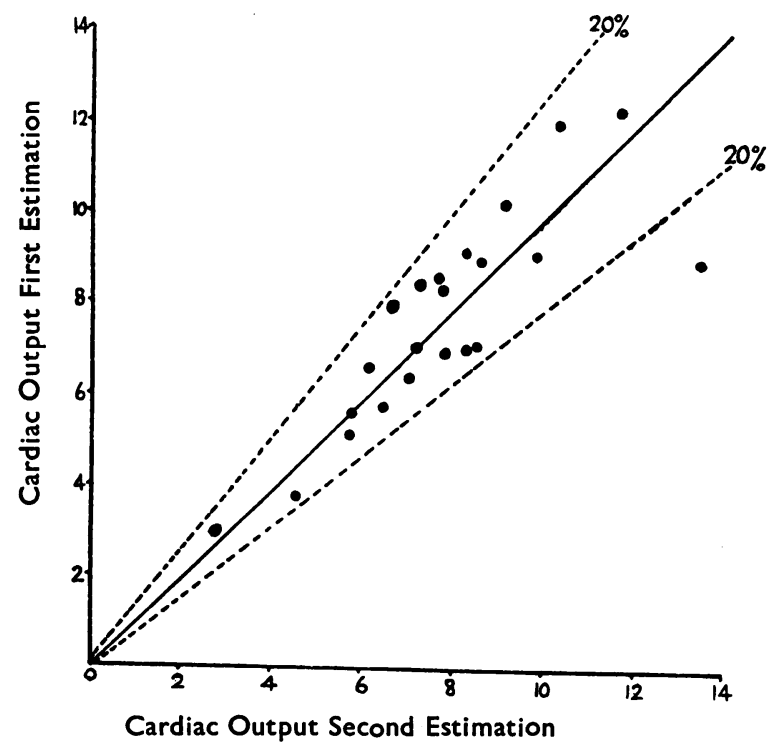

FIG. 7.-Duplicate series of cardiac outputs determined by the oximeter method. 
TABLE II

Duplicate Series (Oximeter Method)

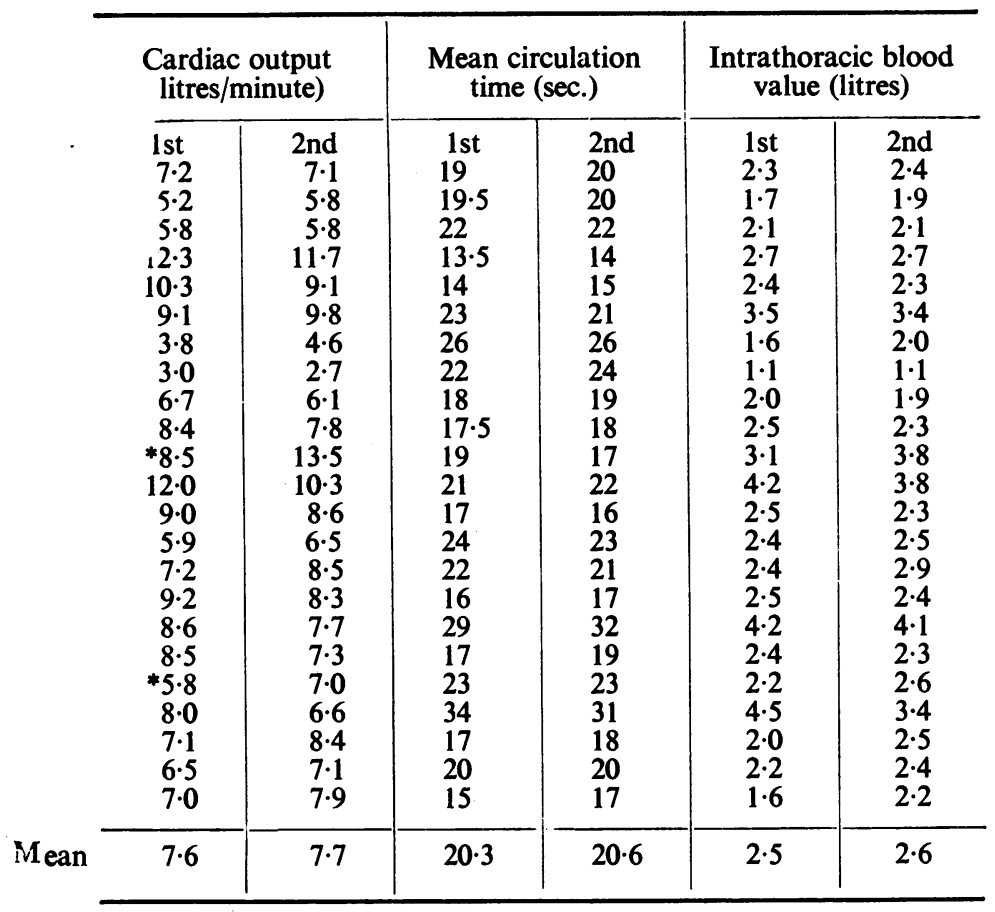

Analyses of Variance

\begin{tabular}{|c|c|c|c|c|}
\hline $\begin{array}{l}\text { Between duplicates } \\
\text { Between cases .. } \\
\text { Residual }\end{array}$ & $\begin{array}{l}. . \\
\ddot{.}\end{array}$ & $\begin{array}{c}\text { Sum } \\
\text { squares } \\
21 \\
20,453 \\
2,155\end{array}$ & $\begin{array}{c}\text { Degrees of } \\
\text { freedom } \\
1 \\
22 \\
22\end{array}$ & $\begin{array}{c}\text { Variance } \\
21 \\
930 \\
98\end{array}$ \\
\hline Total & . & 22,629 & 45 & \\
\hline
\end{tabular}

\section{Discussion}

For the estimation of arterial oxygen saturation, the oximeter offers a method which is both simple and painless. Its accuracy over the milder degrees of anoxæmia is sufficient for clinical purposes. Where the saturation falls below 70 per cent or when polycythæmia of more than a mild degree is present, the instrumental error rapidly increases. Its value in children, where arterial puncture is undesirable from all points of view, has already been cited. Occasionally, in very small children, and nearly always in babies, the ear lobule has been too small to take the ear piece. A miniature version of the same ear piece as described by Crehan et al. (1950) meets this criticism.

When used with Evans Blue dye the oximeter has obvious potentialities in the screening of patients suspected of having congenital heart disease. After giving an objective measure of any anoxæmia that may be present and the effect of exercise on the arterial oxygen saturation, injection of the dye will reveal the presence of a shunt and the predominant direction of flow.

As a means of measuring cardiac output, this method described is free from any danger to the 
patient and the only discomfort felt is from two venepunctures. The results obtained compare well with those derived by other methods. Perhaps the comparison with the Hamilton dye method is the fairest, as it is only in these cases that the output comparisons were made simultaneously. The replotted time concentration curves obtained by these two methods, an example of which is illustrated in Fig. 8, show how close this comparison is.

In Table II is shown the duplicate series of cardiac output determinations, and also the calculated mean circulation times and intrathoracic blood volumes, for each subject studied. It will be seen that the duplicate circulation times differ remarkably little, but that the difference in cardiac outputs differ much more. We conclude from this that the major source of error lies in the calibra-

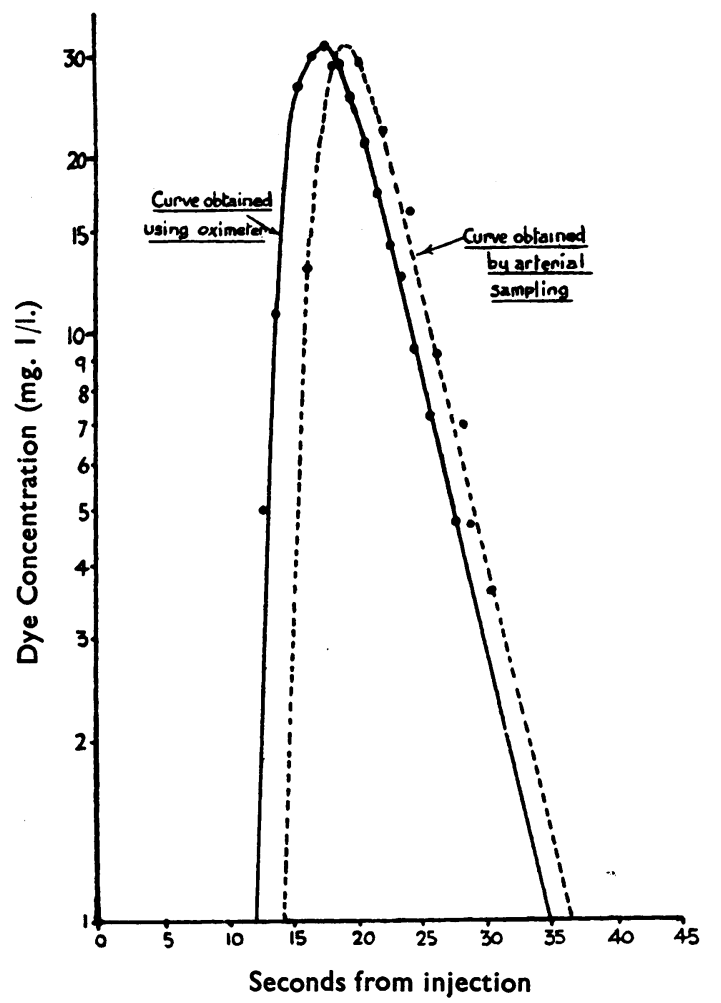

FIG. 8.- Replotted time concentration curves obtained from simultaneous oximeter recording and from arterial sampling (Hamilton method).

tion of the dye concentration in plasma. This may arise from inaccurate estimation of the dye concentration in the plasma sample taken after mixing or from a false reading of the oximeter at the time of sampling. This calibration of the time concentration curve in terms of plasma concentration of dye is the main source of error for this technique. Consideration of the two cases indicated in Table II illustrates this point as in these two cases the dose of dye injected was very different on the two occasions. Although the mean circulation times did not differ, the colorimetric error in these two cases was enhanced by the difficulty of estimating a very low plasma dye concentration in one of the two determinations. This point amplifies our earlier statement that the dose of dye injected should exceed $15 \mathrm{mg}$. if the cardiac output is to be calculated with reasonable accuracy. However, although not quite so good, the duplicate results compare favourably with those obtained using the more conventional Hamilton dye technique which requires arterial puncture (Ball $e t$ al., 1952).

While the main difficulty in using low concentrations of dye is in achieving accurate colorimetry, it too has some bearing on the dye concentration curve. Where the dye concentration is low the 
dip in the curve is shallow, replotting is tedious, and there is a wider margin of error. In the same way, where the curve is shallow and protracted, as will occur with cardiac failure or with large hearts, greater ease in replotting and calibration and overall accuracy is achieved if a larger dose of dye is given, $20-25 \mathrm{mg}$. As in the Hamilton technique in general when cardiac failure, cardiac enlargement, or valvular disease is gross, the error of the method is greatly increased.

The dose of dye is a limiting factor when repeated estimations of cardiac output are desired. After $40-45 \mathrm{mg}$. total dose there may be a slight suggestion of blueness of the subcutaneous tissues - temporary and harmless but nevertheless undesirable. Duplicate outputs can be done at about monthly intervals, the time needed for disposal of the dye particles into the recesses of the reticuloendothelial system.

Many subjects have a steady resting level of arterial oxygen saturation, which remains unaltered even by 1 per cent over long periods of time. However, changes in posture or emotional tone, even in these regular breathers, will alter the saturation level. Some people, even when completely relaxed, breathe irregularly and arterial oxygen saturation varies 1-2 per cent from time to time. To eliminate these variations, which make accurate calibration difficult (though not impossible, as respiratory fluctuation can be recognized as such), oxygen by mask is given during the period of estimation. We have no evidence that this seriously alters cardiac output, although its use may limit the value of the method for measuring absolute values for cardiac output under basal conditions. The main value of the method lies in its ease and repeatability over periods of time. Thus changes in cardiac output estimated under similar conditions may be studied under the influence of therapy in a variety of conditions.

\section{SUMMARY}

Some clinical uses of the ear oximeter are described. Its value as an instrument for measuring changes in arterial oxygen saturation is discussed.

In congenital heart disease together with the use of Evans Blue dye it may be a useful diagnostic aid.

A method for determining cardiac output by the use of Evans Blue is described and compared with other methods. The accuracy of this method appears to be adequate for clinical use.

We should like to express our gratitude to Professor J. McMichael for his interest and help, to Dr. I. G. Milne of Montreal for much assistance and to Dr. I. D. P. Wootton for statistical advice.

\section{REFERENCES}

Ball, J. D., Kopelman, H., and Witham, A. C. (1952). Brit. Heart J., 14, 363.

Beard, E. F., and Wood, E. H. (1951). J. Applied Physiol., 4, 177.

Comroe, J. H., Jr., and Botellis, S. (1947). Amer. J. med. Sci., 214, 1.

Crehan, E. L., Kennedy, R. L. J., and Wood, E. H. (1950). Proc. Mayo Clin., 25, 392.

Gilmore, R. H., and Kopelman, H. To be published.

, Kopelman, H., McMichael, J., and Milne, I. G. (1952). Lancet, $2,898$.

Hamilton, W. F., Moore, J. W., Kinsman, J. M., and Spurling, R. G. (1932). Amer. J. Physiol., 99, 534.

-, Riley, R. L., Attyah, A. M., Cournand, A., Fowell, D. M., Himmelstein, A., Noble, R. P., Remington, J. W., Richards, D. W., Jr., Wheeler, N. C., and Witham, A. C. (1948). Amer. J. Physiol., 153, 309.

Kopelman, H., and Lee, G. de J. (1951). Clin. Sci., 10, 383.

Kramer, K. (1934). Ztschr. f. Biol., 95, 126.

McMichael, J., and Sharpey-Shafer, E. P. (1944). Brit. Heart J., 6, 33.

Matthes, K. (1935). Arch. exp. Path. G. Pharmak, 179, 698.

(1936). Arch. exp. Path. G. Pharmak., 181, 630.

Millikan, G. A. (1942). Rev. Scient. Instruments, 13, 434.

Nicolai, L. (1932). Arch. ges. Physiol., 229, 372 .

Swan, H. J., Zapata-Ziaz, J., and Wood, E. H. (1953). Circulation, 8, 70.

Van Slyke, D. D., and Neill, J. M. (1924). J. Biol. Chem., 61, 523 .

Wood, E. H., and Geraci, J. E. (1949). J. lab. Clin. Med., 34, 387. 